\title{
Influence of Free Quenching on Mechanical Physical and Thermal Properties of High Density Polyethylene
}

\author{
Leila .Latreche Farid.Rouabah Nacereddine. Haddaoui \\ Laboratory of Physical Chemistry of High Polymers, Ferhat Abbas University, Setif 1-Algeria19000
}

\begin{abstract}
In this study, the effects of free quenching on mechanical physical and thermal behaviours of high density Polyethylene (PEHD) have been investigated. Three different thermal treatments were used: A first free quenching from the melt state to air, a second free quenching from $130^{\circ} \mathrm{C}$ to different temperatures and finally an annealing. The results have shown that an improvement of the impact strength and elongation at break can be obtained after a first quenching to air. However, a second quenching at $0^{\circ} \mathrm{C}$ gives better results and a correlation between the mechanical and thermal properties is observed. The improvement of these properties is obtained to the detriment of other properties like elasticity modulus, density, vicat softening temperature (VST) and heat distortion temperature (HDT). The improvement of impact strength and elongation at break after the second quenching is probably linked to the existence of a relaxation mode located around this temperature.
\end{abstract}

Keywords: free quenching; polyethylene, mechanical, physical, thermal.

DOI: $10.7176 / \mathrm{CPER} / 59-03$

\section{INTRODUCTION}

High density polyethylene PEHD is one of the most important commodity polymers which is widely used in various applications. Because of its good processability, relatively high mechanical properties, great recyclability, and low cost, PEHD has found a wide range of applications in household goods and packaging [1-2].

The generation of residual stresses (RS) is known to improve Izod impact strength of amorphous polymers like polycarbonate [3].The study of the effect of residual stresses (RS) induced by free quenching on the mechanical behaviour of semi-cristalline polymers is one way to understand the relationship between the microstructure and the macroscopic properties of macromolecules such as polyethylene.

Residual stresses (RS) in inorganic and polymeric glasses have received a large attention in the past because of their technological importance [4-6]. In amorphous polymers, the RS are in fact totally attributed to volumetric fluctuations, associated with the relaxation kinetics at the glass transition temperature $\left(T_{\mathrm{g}}\right)$. This leads to an incomplete viscoelastic relaxation during solidification. RS are commonly classified as residual microstresses and residual macrostresses [7]. In a laboratory scale, two methods are available for introducing RS in polymers: non-uniform cooling (thermal quenching) and non-uniform plastic deformation (cold working). In this study, the RS term refers to those produced by transient thermal gradients. Many attempts have been made to determine the influence of residual stresses on properties of moulded polymers. During processing the residual stresses are introduced by nearly all techniques used for polymer manufacturing. For example the variations of the injection molding conditions may produce changes of molecular orientation. In order to avoid a contribution of flow induced orientation, free quenching experiments have been used by several investigators on semicrystalline and amorphous polymers [8-10].

The objective of this work is to investigate the effect of quenching temperature on physical, mechanical and thermal properties of high density polyethylene PEHD, and on the other hand, to try to improve some of these properties. The purpose of the present contribution is to give extensive experimental results that may lead to a better understanding of RS and their relations to some properties of high density polyethylene PEHD.

\section{Experimental procedure}

\subsection{Materials}

The polymer used in this study is a commercial high density polyethylene PEHD supplied by l'Entreprise Nationale des Industries Pétrolières (ENIP) of Skikda - Algeria, with a density of about (0.923). The melt index at $230^{\circ} \mathrm{C}$ is $1.20 \mathrm{~g} / 10 \mathrm{~min}$; the melting temperature is $143^{\circ} \mathrm{C}$

\subsubsection{First quench procedure}

Pellets of PEHD were put into the mould and pressed at 25 bars during 8 minutes at moulding temperature $180^{\circ} \mathrm{C}$. Then the samples were immediately quenched from moulding temperature into air during 15 minutes. All samples have $3 \mathrm{~mm}$ of thickness and this step was named "first quench".

\subsubsection{Second quench procedure}

In a second time, another free quenching was carried out for samples moulded at $180^{\circ} \mathrm{C}$ for the first quenching temperature in air. These specimens were heated in an oven at $130^{\circ} \mathrm{C}$ during 2 hours and were immediately quenched a second time into water baths at different temperatures $\left(0,20,30,40,50,60,70,80^{\circ} \mathrm{C}\right)$ and in the air during 15 minutes. This procedure was named "second quench". 


\subsubsection{Annealed samples}

Finally, in order to get a sample as reference, an annealing is performed. Annealed specimens were prepared using samples first quenched in air. Then, these samples were heated at $130^{\circ} \mathrm{C}$ during 2 hours and finally slowly cooled in the oven until room temperature at a rate of about $\left(10^{\circ} \mathrm{C} / 30 \mathrm{~min}\right)$. These samples were named "annealed samples".

\subsection{Tensile test}

The tensile properties were determined using dumbbell specimens of $115 \mathrm{~mm}$ length, $13 \mathrm{~mm}$ wide, and a gauge length of $20 \mathrm{~mm}$. The tests were carried out using a universal testing machine with a crosshead speed of 10 $\mathrm{mm} / \mathrm{min}$. From the experimental stress-strain curves, tensile properties (modulus of elasticity, and elongation at break) of the quenched PEHD were obtained. Five specimens were tested and the average values were used for the data plot.

\subsection{Notched Izod impact strength}

This test method is used to determine the resistance of plastics to breakage by flexural shock as indicated by the energy extracted from standardized pendulum type hammers, mounted in standardized machines, in breaking standard specimens with one pendulum swing. Izod impact strength properties were determined at room temperature with a CEAST 6546 machine provided with a $15 \mathrm{~J}$ pendulum according to the ASTM D256-73, and using specimens of $3 \times 12.7 \times 63 \mathrm{~mm}^{3}$ dimension. Some specimens were moulded with a notch radius of $0.5 \mathrm{~mm}$. For others specimens a notch of radius $0.5 \mathrm{~mm}$ were machined. The radius was chosen such that the tip of the notch was located in the residual compressive zone. At least 5 specimens were tested and the average value was used for the data plot.

\subsection{Density measurement}

The specific gravity or density of a solid is a property that can be measured conveniently to identify a material, to follow physical changes in a sample, to indicate degree of uniformity among different sampling units or specimens, or to indicate the average density of a large item. Density is measured with a pycnometer by weighing a substance, usually in the liquid state, that is placed in the device and fills the pycnometer to a mark on its neck or to the upper edge of a capillary tube, corresponding to the nominal volume of the pycnometer. The major advantages of the pycnometric method for the determination of density are high accuracy of measurement (to $10^{-5} \mathrm{~g} / \mathrm{cm}^{3}$ ).

\subsection{Heat distortion temperature}

The heat distortion temperature HDT was obtained in accordance with ASTM D648, which describes HDT as the temperature where a specimen $\left(3 \times 13 \times 127 \mathrm{~mm}^{3}\right)$ deflects by $0.25 \mathrm{~mm}$ under $1.8 \mathrm{MPa}$ while heated in an oil bath at a rate of $2{ }^{\circ} \mathrm{C} / \mathrm{min}$. At least 4 specimens were tested and the average value was used for the data plot.

\subsection{Vicat softening temperature}

Vicat softening temperature tests VST were utilised to determine the softening temperature of the material. A Zwick Vicat softening temperature tester at $50 \mathrm{~N}$ force and $5{ }^{\circ} \mathrm{C} / \mathrm{min}$ heating rate was utilised to determine temperature at which the indentor penetrates $1 \mathrm{~mm}$ into the material.

\section{Results and discussions : Effect of second quenching}

\section{1 Impact strength and elongation at break}

Figures. 1 and 2 show the notched and unotched Izod impact strength $\left(a_{n}, a_{k}\right)$ as a function of second quenching temperature for the sample of PEHD first quenching in air. The values of Izod impact strength reach a maximum for the second quenching temperature of $0^{\circ} \mathrm{C}$. On the other hand, one can notice that the Izod impact strength $\left(a_{k}\right)$ values decrease with the increase of the second quenching temperature. For example for unotched specimens Izod impact strength $\left(a_{k}\right)$ decreases from $18,102 \mathrm{~kJ} / \mathrm{m}^{2}$ to $15,2 \mathrm{~kJ} / \mathrm{m}^{2}$ for quenching temperatures ranging between $0^{\circ} \mathrm{C}$ and $80^{\circ} \mathrm{C}$, for moulding temperature of $180^{\circ} \mathrm{C}$. These variations are more prominent for the annealed sample $\left(12.292 \mathrm{~kJ} / \mathrm{m}^{2}\right)$. 


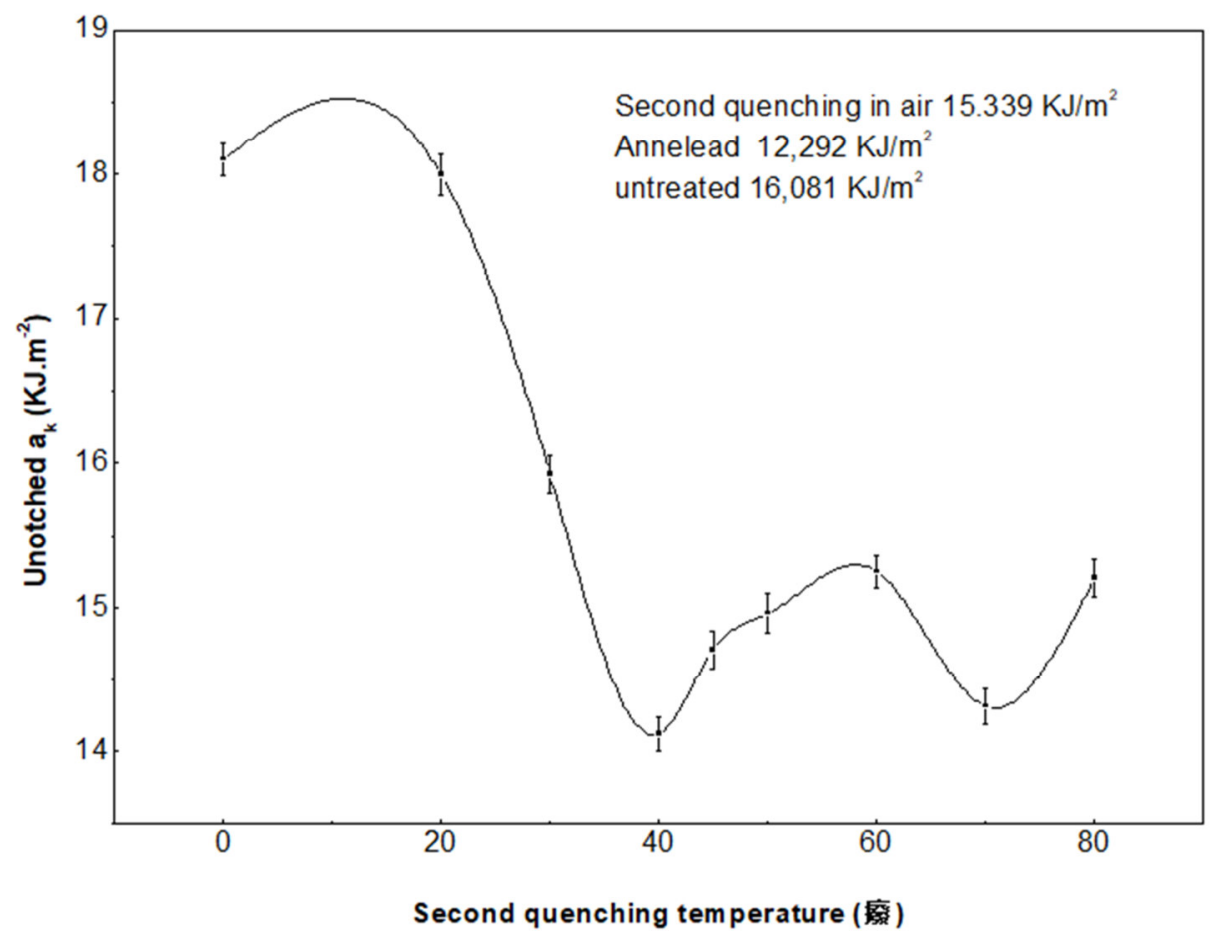

Figure.1. Unotched Izod impact strength of PEHD as a function of second quenching temperature

Generally the impact resistance of semi-crystalline polymers depends on the crystalline phase that develops during heat treatment. There is a drop in the impact resistance with increasing crystallinity.

The elongation at break as a function of second quenching temperature is presented in Figure.3. The highest elongation at break is obtained at second quenching temperature of $0^{\circ} \mathrm{C}$., which is again related to a good ductility under these conditions. The results show a dramatic decrease of the elongation at break values as second quenching temperature increases.

The free volume increase was verified by performing density measurements. These results will be presented in the following part. As the impact strength can be correlated with the ability of polymer chains to execute segmental motion and hence dissipate the energy associated with crack propagation, an increase in free volume may also be responsible of the increase of impact strength.

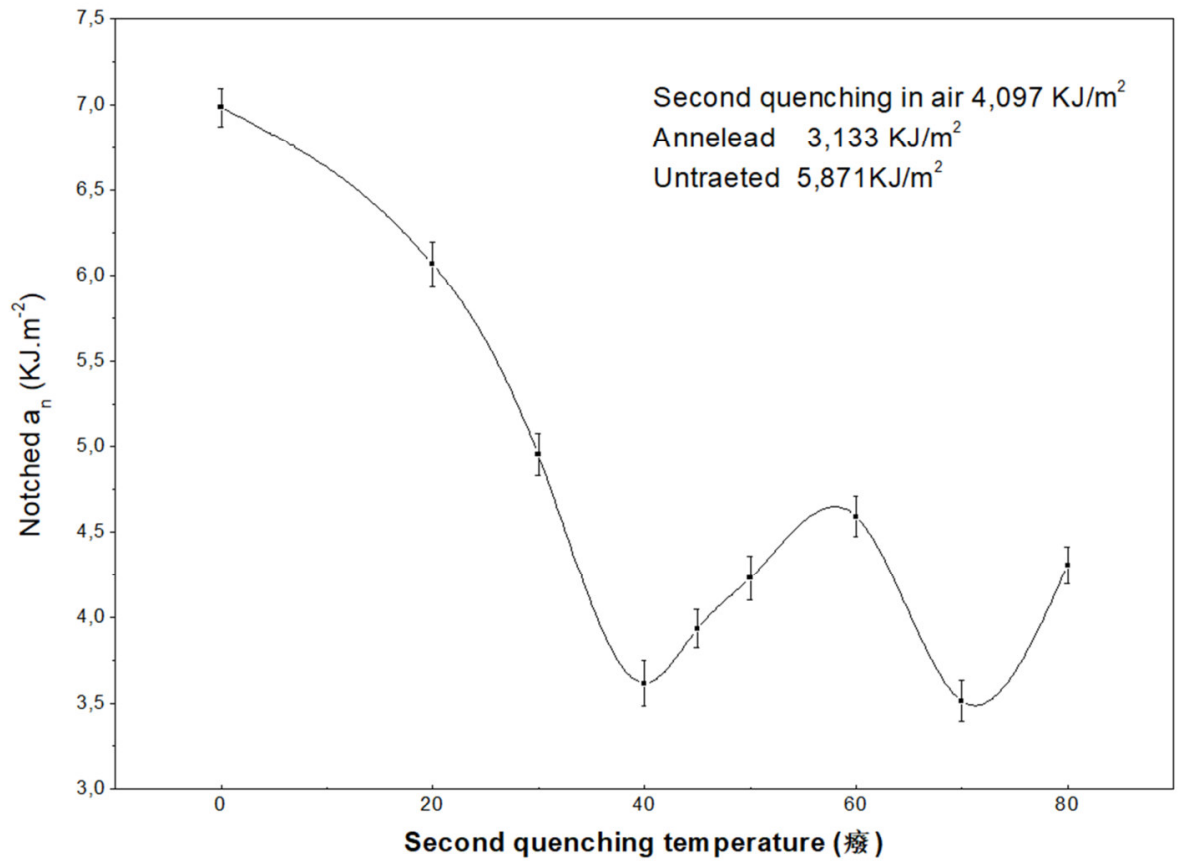

Figure.2. Notched Izod impact strength of PEHD as a function of second quenching temperature 


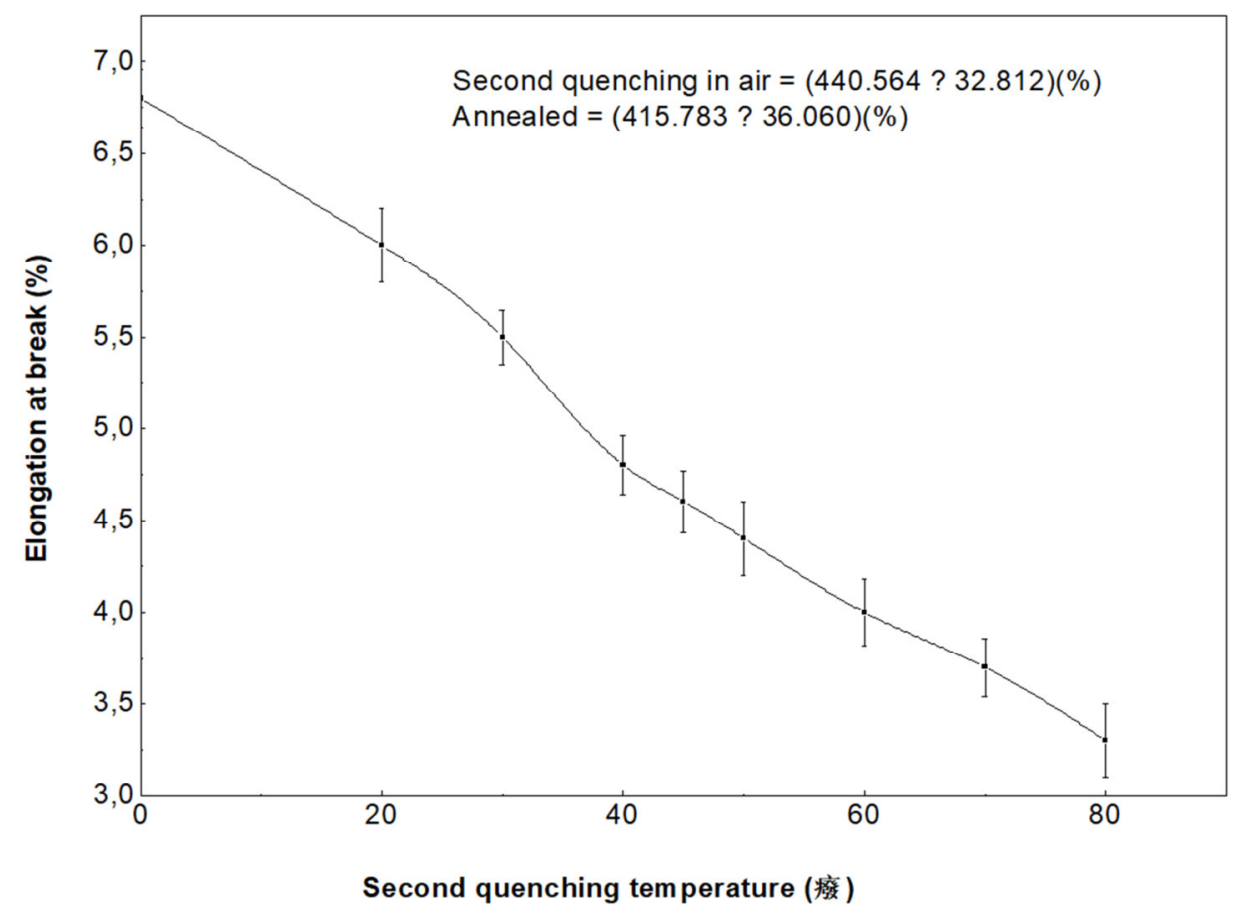

Figure.3. Elongation at break of PEHD as a function of second quenching temperature

\subsection{Density and modulus of elasticity}

The variations of density and modulus of elasticity as a function of the second quenching temperature are shown in Figures. $\mathbf{4}$ and $\mathbf{5}$ respectively. Density measurements give an indication of gross molecular readjustments of the high density polyethylene samples. A decrease in density for a crystalline material implies a decrease in crystallinity and vice versa. The density increases clearly as the second quenching temperature increases. In the faster cooling case, which corresponds to a $0^{\circ} \mathrm{C}$ second quenching temperature, the macromolecules have less time to reorganize. This induces an increase of the free volume and therefore a lower density. It has been also reported that the free volume (and hence density) is governed by two effects, the rate of temperature change and the thermal stresses [11-12].

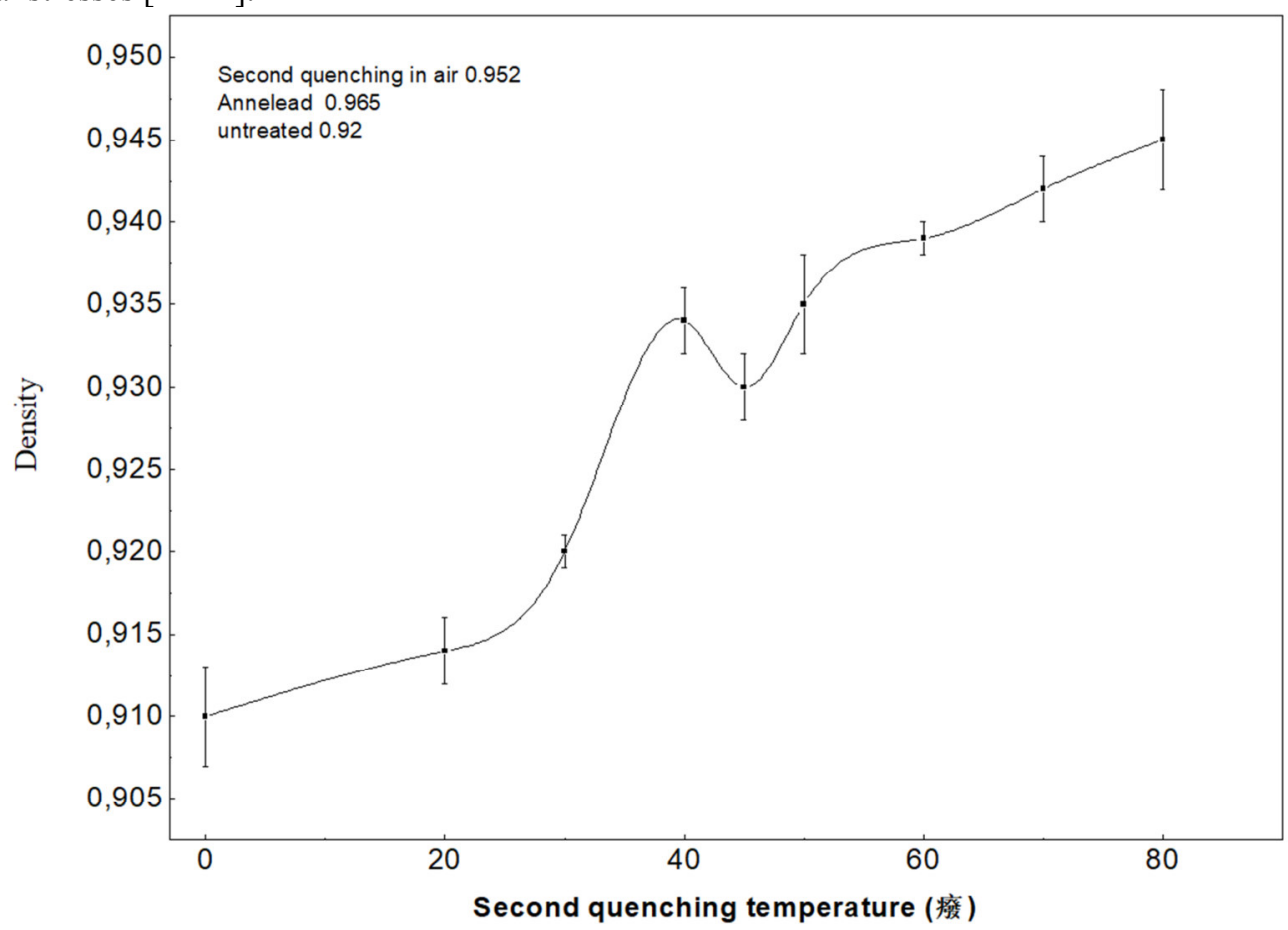

Figure.4. Density of PEHD as a function of second quenching temperature

According to Van Krevelen the density $(\rho)$ is correlated to the Young's modulus (E): $\mathrm{E} \propto \rho^{7}$ i.e. this means 
that samples having a lower density have also a lower Young's modulus [13]. Annealing tends to increase the density (and crystallinity). It is important to note that the samples second quenched at $0{ }^{\circ} \mathrm{C}$ have consistently slightly lower density (and crystallinity) than the samples second quenched in air.

On the other hand, the annealing leads to a significant increase in the modulus of high density polyethylene PEHD (1219 MPa) compared to the quenched material; which varied between $642 \mathrm{MPa}$ and $1110 \mathrm{MPa}$, this is largely explained by the significant gain of crystallinity associated with this heat treatment. HOWEVER, During annealing, thermal residual stresses are more or less eliminated so it is probably due to the origin of structural stresses which dominate, where the values of the modulus are higher compared to the values of quenched samples.

Quenched samples at high temperatures are consistently more rigid than those from rapid quenching. This is mainly due to different stresses of structural origin that probably increase the degree of crystallinity.

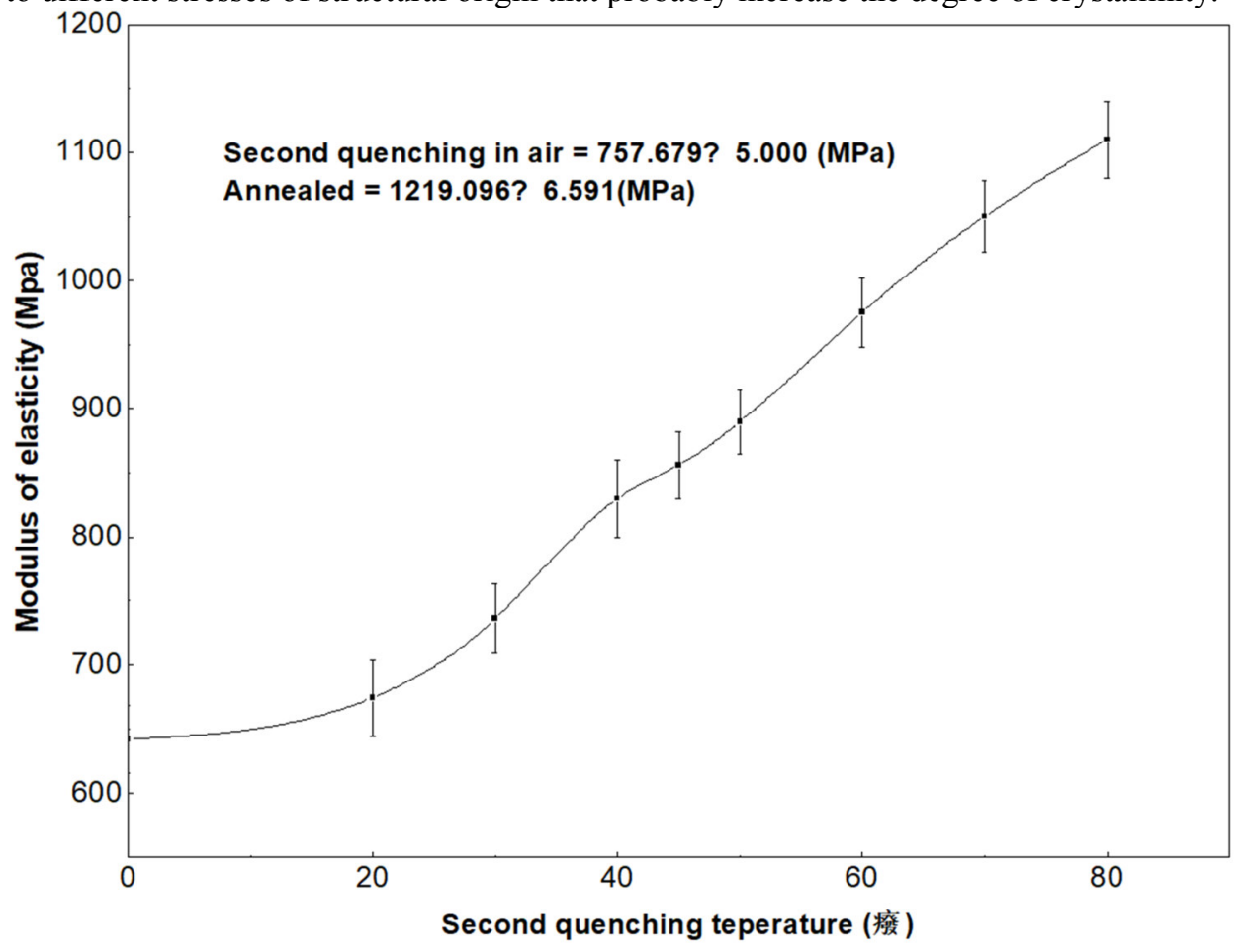

Figure.5. Modulus of elasticity of PEHD as a function of second quenching temperature

\subsection{VST and HDT}

The Vicat softening point is sensitive to compressive stresses; it decreases when compressive stresses increase. It is also sensitive to free volume, which favours the physical sliding of molecular segments. The variation of VST as a function of second quenching temperature for the sample of high density polyethylene PEHD first quenching in air is shown in Figure. 6. It is observed that a low second quenching temperature decreases the VST. This is due to larger compressive stresses and higher free volume for this quenching temperature. 


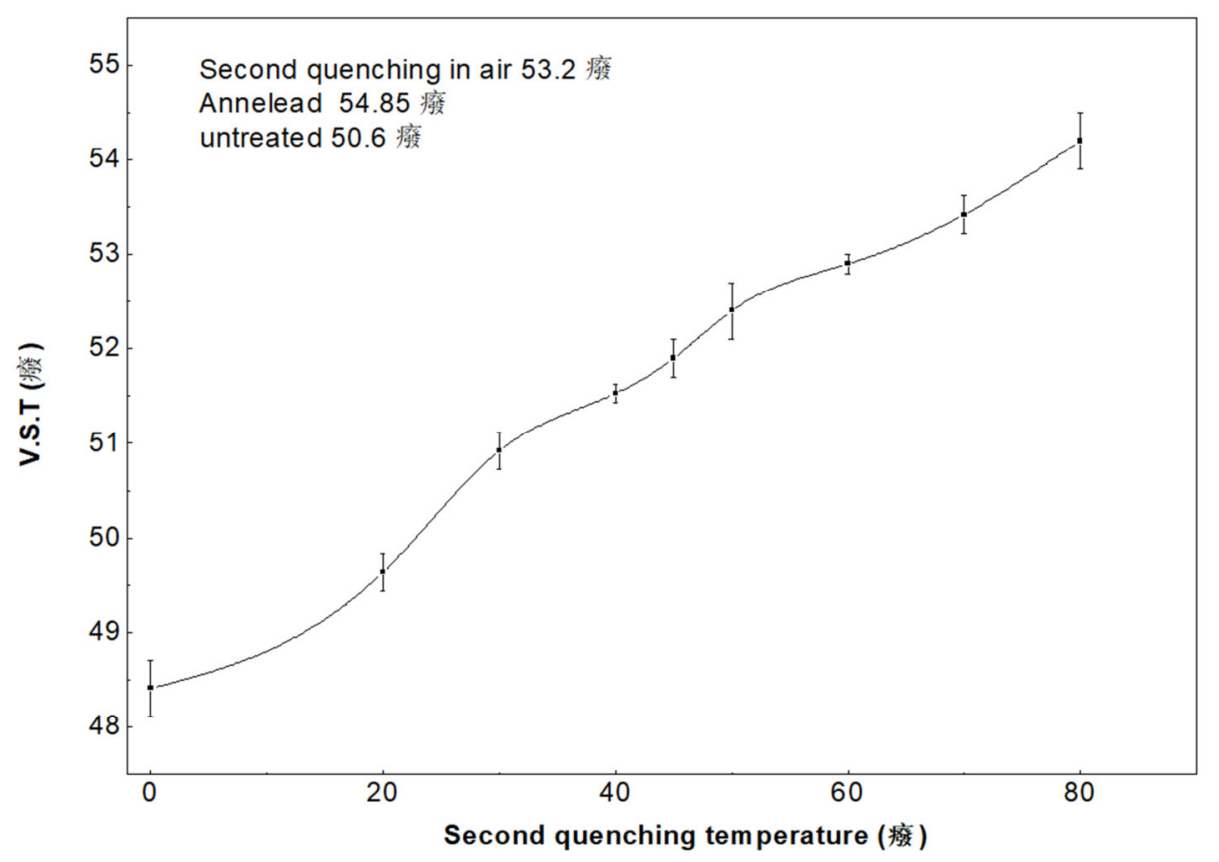

Figure.6. Vicat softening temperature of PEHD as a function of second quenching temperature

As observed for the modulus of elasticity, Vicat softening point and density, the heat distortion temperature (HDT) decreases when the second quenching temperature decreases Figure.7. HDT decreases when tensile stresses exist in the sample because they increase the total tensile stress applied to the sample. So, HDT evolves like the Vicat softening point. In other respects, Siegmann et al. without calculating the change in free volume speculated that the increase in HDT was related to the decrease of free volume as a result of relaxation of thermal stresses and molecular orientation [6]. As HDT and density vary in the same way, the evolution of HDT may also be partially due to the evolution of free volume with the different thermal treatments.

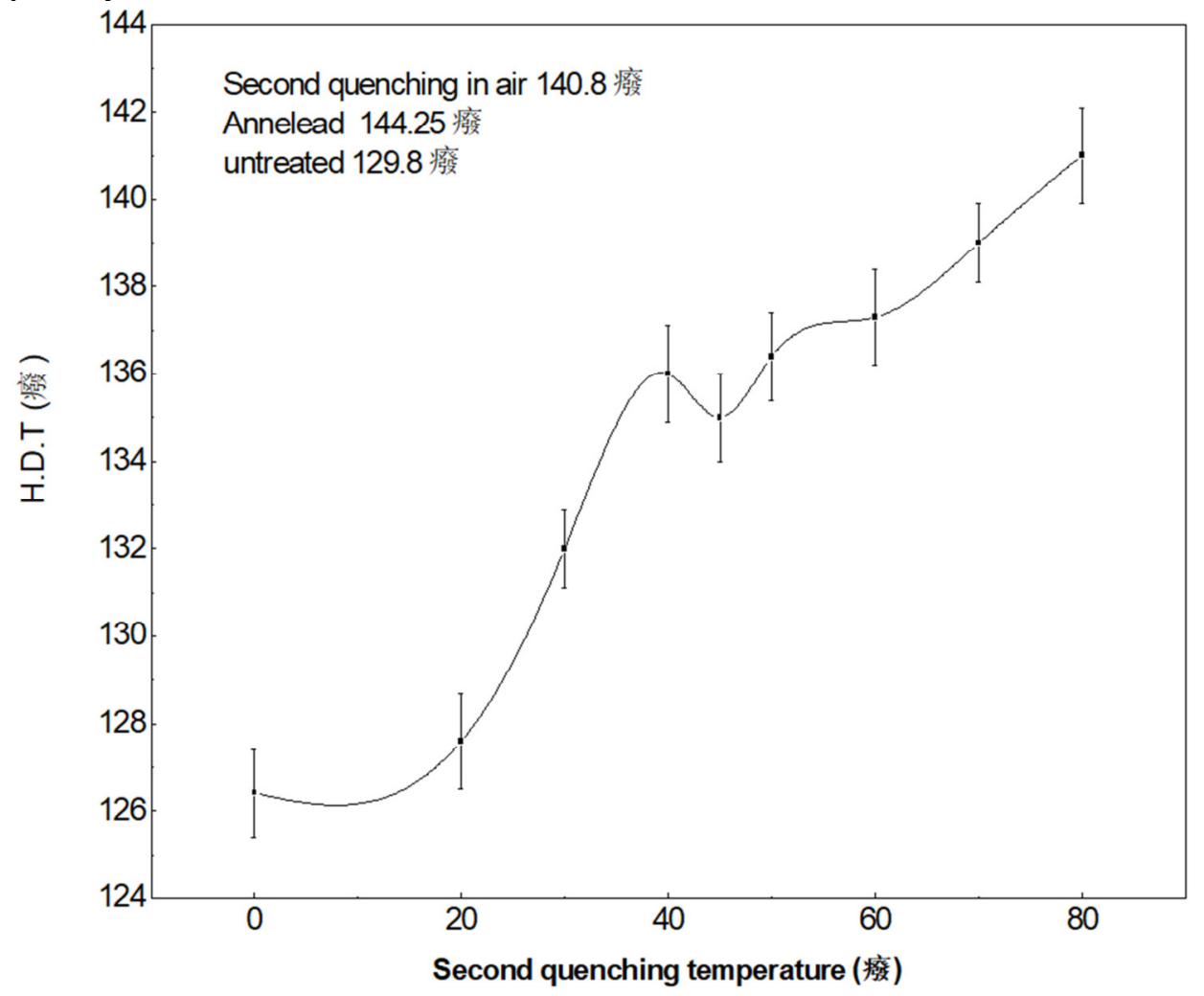

Figure.7. Heat distortion temperature of PEHD as a function of second quenching temperature

\subsection{Summary of second quenching procedure influence}

The influence of heat treatment (quenching and annealing) will appear on all the properties studied. The 
properties of the samples obtained after second quenching at $0^{\circ} \mathrm{C}$ and $20^{\circ} \mathrm{C}$ (corresponding to a rapid quenching) are very distinct from properties which corresponding to a second quenching at 60 , and $80{ }^{\circ} \mathrm{C}$ in air (corresponding to a slow quench).

To summarize, PEHD properties depend strongly on second quenching conditions. A faster cooling, corresponding to the lower quenching temperature, generates probably more residual stresses and free volume; this increases the Izod impact strength and decreases the modulus of elasticity, density, VST and HDT.

\section{Acknowledgments}

Authors gratefully acknowledgethe "Université Ferhat Abbas, Sétif.1.UFAS ,Algeria" for the financial support of this investigation.

\section{Conclusion}

The effect of quenching process on mechanical and thermal properties of PEHD was investigated via impact, tensile and thermal measurements. It was shown that a larger ductility can be obtained by quenching the samples at the lowest temperature $\left(0^{\circ} \mathrm{C}\right)$ from $130^{\circ} \mathrm{C}$. This quenching generates probably more residual stresses and free volume which increase the Izod impact strength and elongation at break, and decrease the modulus of elasticity, density, VST and HDT.

The minimum of density reached after a second quench between $130^{\circ} \mathrm{C}$ and $0^{\circ} \mathrm{C}$ was associated with the presence of more free volume, which leads to a higher molecular mobility. This explains the increase of Izod impact strength and elongation at break, and the decrease of modulus of elasticity, VST and HDT.

\section{References}

[1]L,Latreche ,N, Haddaoui, M, E,Cagiao ,Rus .J. App. Chem. 89,10(2016)1713-1721.

[2] K ,Yang,Q, Yang,G, Li, Y,Sun,D, Feng, Mater Lett; 60(2006)805-809.

[3] F,Rouabah, M,Fois, L,Ibos, A,Boudenne, C,Picard, D,Dadache, N, Haddaoui, J.Appl. Polym .Sci. 109, (2008) 1507.

[4] B,D ,Aggarwala, E,Saibel, Phys. Chem. Glass. 2(1961)137.

[5] E,H, Lee,T,G, Rogers, T,C,Woo , J .Am .Ceram .Soc. 48(1965) 480.

[6] A,I, Isayev, Polym. Eng .Sci. 23(1983)271.

[7] A,Siegmann, A,Buchman, S,Kenig, Polym. Eng. Sci. 22(1982) 1,40.

[8] X,Guo, A,I,Isayev , J .Appl .Polym. Sci. 75(2000)1404.

[9] G,D, Shyu, A,I ,Isayev, C,T, Li, J .Polym. Sci : Part B : Polym Phys; 41(2003)1850.

[10] L,E, Hornberger,G, Fan, K,L,DeVries , J .Appl. Phys. 60, 8(1986)2678.

[11]L, Latreche, N,Haddaoui, M,E,Cagiao,Rev .Roum. Chim .62,3(2017)267-276.

[12] Y,Shan, R,F,Boehm, K,L,DeVries, Polymer.31,5(1990)935.

[13] D,W,Van Krevelen, Properties of Polymers, Amesterdam, Elsevier,(1972). 